\title{
A Memória Institucional - Santa Casa POA/RS
}

\section{La Memoria Institucional - Santa Casa POA/RS}

\author{
Ma. Margareth de Oliveira Michel' ${ }^{1}$; Ma. Jerusa de Oliveira Michel². \\ 1 margareth.michel@gmail.com, Universidade Católica de Pelotas; \\ 2 jerusa.michel@gmail.com, Universidade Católica de Pelotas.
}

\begin{abstract}
Resumo
O trabalho analisa os enfoques sobre a memória organizacional e como esse trabalho é articulado: questões estratégicas de resgate e construção de memória; a emergência do "mercado de memórias", a relação entre a cultura e a memória organizacional, os instrumentos utilizados. São desenvolvidas reflexões teóricas nas áreas estudadas aliadas ao estudo de caso da Santa Casa de Misericórdia de POA.
\end{abstract}

Palavras-Chave: Comunicação Organizacional e Memória Institucional.

\section{Resumen}

El trabajo analiza los enfoques de la memoria de la organización y cómo este trabajo se articula: cuestiones estratégicas de rescate y construcción de la memoria; el surgimiento de "mercado de recuerdos", la relación entre la cultura y la memoria de la organización, los instrumentos utilizados. Reflexiones teóricas se desarrollan en las áreas estudiadas aliado para el estudio de caso de la Santa Casa de Misericordia de POA.

Palabras claves: Comunicación organizacional y la memoria institucional.

\section{Introdução}

Vivemos um tempo complexo, pois na sociedade contemporânea, muitas utopias chegaram ao fim: a crença no futuro, na evolução da sociedade. Na abordagem de Bauman (2001), que chama de modernidade líquida ${ }^{1}$ a época atual, as relações que na era pré-moderna eram consideradas 'sólidas', tornaram-se 'líquidas', fluídas, voláteis, incertas e inseguras, efêmeras. O autor refere-se ao mundo do trabalho como 'um campo fluído, desregulamentado', em que as relações de trabalho são cada vez mais desgastadas, com empregos temporários, meia jornada, empregos em que as relações de empregado-empregador (trabalhadores que são Pessoa Jurídica) são cada vez mais complexas.

Com o advento das tecnologias, e em função das muitas e rápidas mudanças, foram desencadeados efeitos sociais que afetaram o mundo do trabalho, dos trabalhadores e das organizações, causando mudanças nos processos organizacionais. Relacionando a todas estas

\footnotetext{
${ }^{1}$ É nesta época que toda a fixidez e todos os referenciais morais da época anterior, denominada por Bauman como modernidade sólida, são retiradas de palco para dar espaço à lógica do agora, do consumo, do gozo e da artificialidade.
} 
mudanças a adoção (especialmente pelas organizações brasileiras) de diferentes correntes filosóficas de gestão em que as transformações sociais levaram à privatizações e fusões entre organizações, constata-se o abandono de suas referências históricas ou a pouca importância com que foram tratadas, face ao processo cada vez mais acentuado de produção e consumo. Essas mudanças refletiram-se no relacionamento destas com os seus públicos, uma vez que as transformações estruturais repercutiram na identidade e na imagem organizacional. (MICHEL, MICHEL e PORCIÚNCULA, 2013).

Nesse cenário, na visão de muitos autores, ocorre no mundo contemporâneo, uma 'falta de memória', fenômeno que aponta para várias perspectivas, em muitas das quais nossa sociedade comumente é designada 'sociedade sem memória'. Em decorrência das muitas atividades que cada pessoa desenvolve, há pouco ou nenhum tempo para o registro das suas experiências e histórias de vida, pessoal, social e no trabalho.

Pode-se apontar, de acordo com os autores mencionados que há quase um consenso de que a sociedade contemporânea é 'uma sociedade sem memória' seja por conta dos aparatos tecnológicos ou em função das muitas e rápidas mudanças que ocorrem, gerando um movimento contínuo e fluído (BAUMAN, 2001) onde pelo excesso de informações há uma necessidade cada vez maior de dispositivos de armazenamento de informações (NORA, 2000). Nesse contexto, desponta o interesse pela questão da memória.

\footnotetext{
Com o fim das utopias, explicitado na queda do muro de Berlim, em 1989, também ruíram alguns ícones da modernidade: a crença no futuro, a noção de progresso e de evolução das sociedades. O futuro se torna uma incógnita e não uma meta a ser alcançada, o que leva a um retorno ao passado como lugar de nutrição, capaz de jogar luzes sobre o presente. Instalada a crise do futuro, vivida numa espécie de ressaca dos sonhos, encontramos as ruínas do passado, mas não pela perspectiva da história, que jaz em fragmentos. A memória desponta como instrumento fundamental para a formação de identidades nacionais e individuais, ocupando um espaço antes destinado a outras narrativas, como ressalta Joël Candau (1998). (SANTA CRUZ, 2014, p. 179)
}

A memória é então considerada um instrumento que, ao permitir o resgate de algo que pertence ao passado proporciona a preservação de informações essenciais para a experiência individual e social, coletiva. Nela, palavras e ideias podem ser reunidas, imprimindo direções do tempo, permitindo continuidade social e a manutenção não só dos elos sociais, mas da "própria noção de sociedade em que as identidades individuais e coletivas, a possibilidade da construção do conhecimento [...] pode ser considerada uma ferramenta para a construção de uma determinada sociedade, assim como de transmissão cultural” (CRIPPA, 2010, p. 81). 
Shikida e Moura (2007) afirmam que, a memória e suas várias formas de guardar o passado, passa a ser um saber criado e socialmente construído e constituído de vários povos, quando o papel dos sujeitos no processo cumulativo de transformação e a mensagem transmitida são reconhecidos.

O interesse pela temática da memória cresce cada vez mais na sociedade contemporânea, em muitas áreas do conhecimento. Nesse trabalho, direcionamos a pesquisa para a área da memória das organizações contemporâneas, que tem despertado um interesse cada vez maior, buscando conhecer quais as reais condições em que o trabalho com memória é articulado: se estas buscam ampliar vantagens entendidas como estratégicas resgatando e construindo sua memória junto a seus públicos de interesse; se são influenciadas pela emergência do "mercado de memórias", se existe uma relação entre a cultura e a memória organizacional, e se há uma visão mais crítica da comunicação.

\section{A Comunicação Organizacional e a Memória Institucional}

As organizações sociais de qualquer natureza estão inseridas em ambientes altamente competitivos, sujeitos a mudanças constantes e grandes volumes de informações que acontecem num fluxo cada vez mais rápido e intenso. Em decorrência disso, a eficiência nos processos organizacionais é cada vez mais valorizada e terão assegurada sua sobrevivência no mercado aquelas organizações com diferenciais e estratégias adequadas e inovadoras. Considerando este quadro, a comunicação é fundamental para o desenvolvimento e sobrevivência das organizações, especialmente ao que se refere ao relacionamento com seus diversos públicos.

No Brasil os estudos sobre a Comunicação Organizacional são relativamente recentes ${ }^{2}$ e embora muitos pesquisadores se ocupem de suas diversas áreas, há um longo caminho a

\footnotetext{
${ }^{2}$ Destacam-se entre seus precursores Gaudêncio Torquato (1986; 2002), Kunsch (1986; 2003), Cahen (1990), Nassar e Figueiredo (1995), e Bueno (1995), entre outros. Historicamente, Gaudêncio Torquato (2002, p. 3-7) foi um dos estudiosos que se preocupou com o processo evolutivo da comunicação praticada pelas empresas no Brasil que apresenta contendo quatro períodos distintos: o primeiro (em 1950), com o mundo em desenvolvimento e a preocupação das empresas no ambiente interno, a ênfase maior da atividade estava no produto; o segundo (em 1960), a atividade volta-se para os consumidores - mais exigentes, e para o ambiente externo constituindo-se em um sistema híbrido entre as imagens do produto e a da organização; o terceiro (1970 e 1980), mostra a evolução para uma postura estratégica, ultrapassando o patamar tático - focado principalmente na elaboração de instrumentos e nos contatos com o governo e a imprensa, e centrando-se no posicionamento (estabelecido por Al Ries) da empresa ou da marca na mente do consumidor e numa postura mais dinâmica frente ao mercado; e por fim, o quarto (a partir de 1990), que se caracteriza por expressivas mudanças tecnológicas e pela efervescência da globalização, e uma vez consolidada a Comunicação Organizacional no Brasil, é nesse período em que surgem também os estudos relacionados à memória e ocorre o boom da cultura memorialística (HUYSSEN, 2004).
} 
percorrer. Isso se dá porque as organizações são produzidas pelos indivíduos, que são ao mesmo tempo palco de intenso processo de mudança e de produção de imaginário individual e organizacional. Esse, na visão de Freitas (2000), no contexto pós-moderno está articulado a um 'simbolismo nunca visto em nenhuma outra sociedade', e é essa dimensão que permite, no ambiente atual pautado pela complexidade, velocidade, fragmentação dos valores e condutas pessoais, o desenvolvimento das organizações, que 'se colocam como referência social para uma parcela significativa da população'. Aponta também que por serem frutos de interação entre o espaço social e o temporal (produzem uma forma de representação de mundo), que as organizações são capazes de se adaptar às mudanças ocorridas no mundo contemporâneo.

As organizações afetam muitos aspectos da vida das pessoas e a sociedade a vida dos que estão envolvidos com as organizações. A comunicação organizacional é mais que a transferência de informação, pois abrange um processo complexo, multidimensional por meio do qual a organização se posiciona (PAPA et al, 2008).

Esse pensamento aponta para a comunicação como um fator fundamental para que essa adaptação e desenvolvimento ocorram, porque a comunicação é inerente ao ser humano e, portanto, às organizações. Scroferneker (2006) após a realização de inúmeras pesquisas na área esclarece que a comunicação organizacional abrange todas as formas e modalidades de comunicação utilizadas pela organização para relacionar-se e interagir com seus públicos, e destaca que as organizações - empresas, entidades, instituições - sempre se comunicaram. A autora vai mais longe ao afirmar que, nesse século XXI, levando em conta seus diferentes públicos ou stakeholders e a sociedade em geral e sua dinâmica, elas são desafiadas a desenvolver uma comunicação ainda mais consistente, especializada e interativa.

Numa perspectiva mais crítica da própria comunicação organizacional, pode-se observar que na perspectiva funcionalista, ela é vista como um instrumento, uma ferramenta das atividades organizacionais, constituindo o meio pelo qual os atores transmitem suas intencionalidades discursivas (MARCHIORI, 2010), e em abordagens mais interpretativistas (DANIELS, 1997) e mais interpretativas-simbólica (PUTNAM e CHAPMAN, 2005), a questão de que os indivíduos tem capacidade de criar e formar sua própria realidade social por meio da comunicação e interação. Nessa visão, é determinante que os fatores culturais impactam e constituem a organização, e cujos significados são interpretados e divididos de forma consensual, por meio de experiências compartilhadas, e em uma ordem negociada. Se as organizações são instrumentos de repressão ou controle de seu ambiente e de seus públicos é possível que existam distorções no discurso organizacional, cujas escolhas comunicativas 
terão impactos sociais e políticos, repercutindo nos seus públicos de relacionamento e no seu ambiente (COSTA, BARROS e CELANO, 2012).

De acordo com essa visão mais crítica da comunicação organizacional, para que se possa entender melhor o novo papel da comunicação organizacional, é importante chamar a atenção para o fato de que existem duas perspectivas que, segundo Costa, Barros e Celano (2012, p.9) “orientam as escolhas organizacionais no momento de decisão de como criar e implementar as suas estratégias e ações de comunicação (DEETZ, 2005; GOSHAL e TANURE, 2004)". As autoras destacam que a primeira perspectiva a ser considerada refere-se ao relacionamento da organização com seus públicos de interesse, baseado nas relações de poder, no qual as organizações tem dificuldades pois:

[...] De acordo com Aktouf (1996), o próprio termo 'comunicação' contém, etimologicamente, o sentido de 'colocar em comum', de compartilhar. No entanto, a comunicação organizacional, tal como é conduzida, teorizada e tradicionalmente ensinada, visa muito mais o controle e a dominação das situações e de seus públicos do que o 'colocar em comum'. Neste sentido, a comunicação ocorre mais em moldes de fragmentação e anulação do que de construção de processos genuínos de comunicação. (GOSHAL e TANURE, 2004 apud COSTA, BARROS e CELANO, 2012, p.9).

Outra perspectiva, diferente, e mais instrumentalizada, aponta para o fato de "que existe espaço para a construção de relacionamentos mais simétricos e harmônicos entre os públicos de interesses e o dia a dia das práticas organizacionais". (COSTA, BARROS e CELANO, 2012, p.9). Nessa, é possível que haja um futuro compartilhado em que públicos e organizações possam construir discursos "promovendo uma base de confiança mútua e máximo conhecimento recíproco". A partir dessa segunda perspectiva, pode-se entender que a comunicação organizacional expressa uma visão de mundo e valores que deve ser fiel à cultura organizacional, mas que não se limita à divulgação dos produtos ou serviços da organização e que deve acompanhar as tendências da opinião pública.

Assim, atualmente, a comunicação nas organizações cuja prática é mais aberta, por tratar essencialmente de relações humanas, ocupa espaço de função estratégica, como também são estratégicas outras áreas (recursos humanos, financeira, etc). No mundo contemporâneo, a história organizacional conta os fatos e fala sobre os personagens que fazem parte da trajetória de determinada organização, por meio do atributo seletivo da memória, trazendo os elementos referentes à memória coletiva quanto às organizações:

a cultura, os comportamentos, os símbolos, a identidade e a comunicação, o conjunto de elementos que formam a personalidade e a imagem de uma empresa ou 
instituição, são os grandes pilares da memória. E a memória é seletiva: escolhem-se as experiências (boas e negativas) que os inúmeros públicos têm com a organização, seus gestores, empregados, produtos e serviços. (NASSAR, 2007, p. 111)

Segundo os estudiosos (NASSAR, 2007; FIGUEIREDO, 2009; COSTA e SARAIVA, 2011), há um interesse crescente pela temática da memória, e em particular pela memória empresarial/organizacional, que permite identificar o crescimento de uma cultura contemporânea da memória (HUYSSEN, 2004) como já mencionado antes.

A memória é vista a partir de diferentes olhares. É importante para a vida dos grupos sociais porque é o armazenamento e lembrança daquilo que é adquirido por meio da experiência, dessa forma a aquisição de memórias é aprendizado. "Sem memória não há vida. É possível, inclusive, dizer que a vida é uma sequência de memórias" (IZQUIERDO, 2014). A cultura da memória se consolida em "santuários da memória" ou "lugares de memória" (NORA, 1993), criados especificamente para conservar uma memória, uma tradição, uma experiência vivida coletivamente, que podem ser tanto espaços físicos quanto produções abstratas e rituais. Costa e Celano (2012) argumentam que nas organizações, a memória pode ser expressa de várias formas: nos sistemas de informações, na sua arquitetura, nas estratégias adotadas e nos procedimentos operacionais, que estão relacionadas com redução de custos, organização e legitimação das atividades organizacionais, emergência de um mercado de memória, entre outras. Ainda na perspectiva das autoras, uma vez que os relacionamentos das organizações com seus públicos são gerenciados pela comunicação, a gestão da memória organizacional é atribuída a comunicação organizacional, que se materializa de diversas formas, da realização de eventos e comemorações organizacionais, livros e publicações comemorativas, de programas e de centros de memória e documentação, até a criação de museus, entre outras. (COSTA e CELANO, 2012)

Estudiosa da área, Santa Cruz (2014) pesquisou exaustivamente a produção acadêmica de comunicação no Brasil, relacionando memória organizacional e comunicação organizacional, encontrando segundo ela 'chaves conceituais' em que esta relação acontece.

$\mathrm{Na}$ análise do material, identificamos que existem cinco grandes chaves conceituais presentes na produção acadêmica brasileira que relaciona memória e comunicação organizacional: 1) memória como estratégia de comunicação (utilizada como ferramenta de disseminação dos valores das organizações e como meio de ampliar o seu reconhecimento perante a sociedade); 2) memória como cultura organizacional (gestão de pessoas, desenvolvendo o senso de identificação e de pertencimento, por meio da transmissão de valores institucionais); 3) Memória como gestão do conhecimento (a função utilitária da memória no processo de preservação do conhecimento construído na organização, sua recuperação e seu compartilhamento); 4) Memória como trajetória institucional (o resgate da história de uma organização); 5) Memória como saber coletivo (num sentido que quase se aproxima do de cultura, 
como o conjunto de valores, crenças, símbolos e significados de uma coletividade). (SANTA CRUZ, 2014, p. 181)

Costa e Celano (2012) argumentam que nas organizações, a memória pode ser expressa de várias formas: nos sistemas de informações, na sua arquitetura, nas estratégias adotadas e nos procedimentos operacionais, que estão relacionadas com redução de custos, organização e legitimação das atividades organizacionais entre outras.

\footnotetext{
Porém, não obstante a aplicação de novos conceitos de memória face à necessidade de uma comunicação mais aberta e transparente, ela tem sido vislumbrada ainda como uma "ferramenta" (grifo nosso) de comunicação, perspectiva diferente da que propomos aqui por acreditar que essa visão instrumental não dá conta da complexidade das organizações atuais. (BARBOSA, 2010, p.10)
}

Entende-se, que ao tomar para si, a incumbência de gerenciar a memória nas organizações, a comunicação organizacional toma-a como instrumento de comunicação, não só formalizando seu papel estratégico com os públicos internos e externos, mas estabelece relações entre valores, cultura, identidade, os símbolos e os ritos organizacionais (entre outros elementos) e a imagem organizacional pretendida.

\section{A Comunicação Organizacional e a Memória Institucional}

Para o desenvolvimento do trabalho, utilizamos como método geral o HipotéticoDedutivo, por se tratar de um método compreendido em três fases: a primeira parte de uma problemática pré-estipulada; a segunda permite lançar uma possível hipótese ou conclusão para esta problemática; e por fim, a terceira, através da pesquisa de campo, verificar se a hipótese proposta estava correta ou não.

Como método específico, utilizamos o Observacional, que parte de uma situação já existente onde o pesquisador analisa a situação. A proposta do estudo emprega os níveis de pesquisa do tipo exploratória e descritiva, uma vez que se utiliza do método de coleta de dados, e explicativa porque identifica e explica como a Comunicação Organizacional e Memória Institucional se relacionam. O trabalho envolveu levantamento bibliográfico, coleta de materiais em período pré-determinado e entrevista com pessoas que tem experiências práticas com o problema pesquisado.

\section{O objeto de estudo e os resultados encontrados}

Nesse estudo o objeto de análise é a Santa Casa de Misericórdia de Porto Alegre/RS e o material de comunicação produzido impressa e digital na organização. Em 2000, houve toda 
uma reformulação da organização em função das dificuldades econômicas pelas quais passava e naquele período foi estruturada uma Assessoria de Marketing e Comunicação, que entre várias outras atividades começou a estruturar um trabalho de Memória Institucional a partir de documentos, depoimentos e eventos, entre outros. O trabalho foi desenvolvido sendo registrado e disponibilizado no site da Santa Casa, em relatórios anuais, revistas semestrais impressas e digitalizadas, clipagens de notícias e vários outros instrumentos. Com o decorrer do tempo e o crescimento organizacional, esse trabalho foi mudando. Em 2014, foi inaugurado o Centro Histórico-Cultural Santa Casa, com implantação iniciada em 2006 e teve um custo aproximado de R $\$ 13$ milhões (recursos foram captados por meio de leis de incentivo à cultura estadual e federal), que é coordenado por uma historiadora, segundo a qual a demanda pelo espaço nasceu do esforço do complexo hospitalar em conservar sua memória, e fazem parte do acervo documental fotografias, jornais, utensílios médicos, peças encontradas em escavações arqueológicas na área do $\mathrm{CHC}$ e registros de óbitos, os quais estão disponíveis no local desde 2010.

Analisando o referencial teórico pode-se verificar o encadeamento importante e necessário entre os temas propostos: a Comunicação Organizacional, o Jornalismo Empresarial e a Memória Institucional. Através do cruzamento com os dados da organização pesquisada é possível afirmar que o Jornalismo Empresarial, ao registrar por meio de notícias, reportagens e fotos, o cotidiano da organização, aos documentar os fatos ocorridos, acaba por escrever e guardar/arquivar a história organizacional, constituindo-se no viés condutor da memória organizacional. É a memória que a organização pode construir seu aprendizado e construir novas experiências, gerando conhecimento, identidade e história, constituindo-se hoje em importante instrumento da comunicação corporativa, revelando-se como ferramenta para a gestão estratégica dos negócios, permitindo o fortalecimento da marca e identidade da organização e incrementando o relacionamento desta com seus clientes, investidores, parceiros, fornecedores e demais segmentos da sociedade.

No entanto este não é um trabalho integrado entre os setores de comunicação organizacional e a equipe do Centro Histórico. Vários elementos mostram que no caso da organização a memória está sendo utilizada atualmente, como estratégia de comunicação e como trajetória institucional, pois busca ampliar o reconhecimento perante a sociedade ao mesmo tempo em que resgata a história da organização, constituindo-se pelo menos a primeira vista numa memória instrumental do ponto de vista da comunicação organizacional. Se houver uma maior aproximação entre as equipes de comunicação e de gestão do Centro 
Histórico, esse trabalho poderá integrar a cultura da organização (como forma de identificação e pertencimento), como gestão do conhecimento e também como saber coletivo.

\section{Referências}

BARBOSA, Andréia Arruda. O Lugar da Memória Institucional nas Organizações Complexas. Artigo - GT Processos, Políticas e Estratégias de Comunicação Organizacional do IV Congresso Brasileiro Científico de Comunicação Organizacional e de Relações Públicas ABRAPCORP, 2010.

COSTA, Alessandra de S. M.; BARROS, Denise F.; CELANO, Ana. A Construção da Memória Empresarial como Estratégia de Comunicação Organizacional. XXXVI Encontro da ANPAD. RJ - 22 a 26 de set. 2012.

COSTA, A.M.; SARAIVA, L. A. S. Memória e formalização social do passado nas organizações. Revista Adm. Pública, RJ, v.45, n.6, p.1761-1780, 2011.

CRIPPA, G. Memória: geografias culturais entre história e ciência da informação. In: MURGUIA MARANON, E. I. (Org.). Memória: um lugar de diálogo para arquivos, bibliotecas e museus. S. Carlos: Compacta, 2010. p.79-110

FIGUEIREDO, Miriam. (2009) 'Da Memória dos Trabalhadores à Memória Petrobras: história de um projeto'. Dissertação de Mestrado. CPDOC - FGV, Rio de Janeiro. https://bibliotecadigital.fgv.br/dspace/handle/10438/2705

MARCHIORI, Marlene (Org). COMUNICAÇÃO E ORGANIZAÇÃO: Reflexões, Processos e Práticas. São Caetano do Sul: Difusão, 2010.

NORA, Pierre. Entre história e memória: a problemática dos lugares. Revista Projeto História. S. Paulo, v. 10, p. 7-28. -PUC-SP. 1993

SANTA CRUZ, Lucia. Memória e Comunicação Organizacional no Brasil: Interfaces. ORGANICOM - ANO 11 - N. 20 - $1^{\circ}$. SEM. 2014 P. 178

SHIKIDA, A. M.; MOURA, M. A. Memória e redes sociais: informação e conhecimento em relatos orais. In: ENC. NAC. PESQUISA CIÊNCIA DA INFORMAÇÃO. ANAIS. Salvador: UFBA, 2007. 